Journal of Social Sciences 5(4): 301-303, 2009

ISSN 1549-3652

(C) 2009 Science Publications

\title{
Conservation, Renewability and Development of Pabung Patham "Flood Plains" In the Chi River Basin by Community Participation
}

\author{
Suparb Boonchai, Bunsom Yodmali and Therdchai Pantachai \\ Research Institute Northeastern of Art and Culture Mahasarakham University, 44001 Thailand
}

\begin{abstract}
Problem statement: At present Pabang Patham "Flood Plains" have been fading away from new generations' memories because they have known only community forest or "Pa Chum Chon" many kinds of plants, herbs, aquatic animals, wild animals and insects are reduced. Furthermore, some kinds of them are become extinct in the future if no conservation. Approach: A qualitative research was used for the study of conservation, renewability and development of cultural landscapes of Pabung Patham "Flood Plains" in the Chi river basin by community participation. The sample was three groups consisted of 30 key informants, 159 casual informants and 42 general informants. Three research areas were Khon Kaen, Mahasarakham and Yasothon. Results: The result of the study were as follows: (1) at present Pabung Patham have been fading away from new generation memories because they have known only community forest or "Pa Chum Chon" many kinds of plants, herbs, aquatic animals, wild animals and Insects are reduced. Furthermore some kinds of them are become extent in the future if no conservation. (2) Conservation by community participation according to AIC process was operated as follows: A: Appreciation, it was a process of constructing an appreciation. I: Influence, it was a process of constructing an influence on the ways to develop. C: Control, it was a process of constructing the ways to control the project. For this research the controlled factor was planting three kinds of tree and gaining four uses according to the feature of cultural landscapes of flood plains that consisted of planting trees for construction, trees for fruit and trees for fuel. Forest enhanced ecological balance in these ways: (1) enhancing oxygen for human beings (2) enhancing water for human beings (3) enhancing the fertility of soil land (4) enhancing the diversities of culture in case of the forest that Located in different ecology. Four cultural uses that we gained from forest classified into: (1) food was gained from plants, insects, wild animals, aquatic animals. (2) Herbal medicine (3) fuel was gained from trees (4) construction parts were gained from trees. Conclusion/Recommendations: Planting three kinds of tree and gaining four uses enhanced a lot of usefulness for community and reduced effectively the awful situation of global warming, drought storm and flood.
\end{abstract}

Key words: Pubung patham "flood plains", landscape, cultural

\section{INTRODUCTION}

Landscape and physical environment such as weather, earth and water, these are main basic factors which affect the differences of human living behaviors. In the past, human living depended mainly on environment and could say that humans in each society took advantage of environment for leading their life and responded the influence of geographical surroundings which conducted their living patterns. Afterwards, humans could control, adapt and change environmental conditions by using their wisdom and technology for the Purpose of overcoming nature even though they could not control it absolutely. For the reason that humans interact with both humans and nature, thus they must establish rituals, beliefs, customs, traditions and indigenous knowledge.

Both the Mune and Chi river are main rivers which flow through northeast Thailand and join the Mae Khong river so the approximate loss of water is at 25,000-30,000 cubic meters/year and cause drought in summer and flood in rainy season. Thus dam of the Mune and Chi River were constructed under government project that called "The Khong Chi Mune Project. A positive effect of this project was the dams supplied adequately water into the mune and Chi river which caused people can work on their farms or fish cage farms and enhanced their incomes throughout the year, but a negative effect was the disappearance of Pubung Patham which also caused the disappearance of

Corresponding Author: Suparb Boonchai, Research Institute Northeastern of Art and Culture Mahasarakham University, 44001, Thailand 
more hundreds of fishes, because Pabung Patham were sunk into the high level of water and the dams blocked fishes from the Mae Khong River ${ }^{[1]}$.

Pabung Patham is the word that northeast people called a flat area of land near a river that often floods when the water level rises. This area was piled with fertile mud and became a growing area of plants and breeding area of animals. The area likes this spreads into the basin of the Mune, Chi, Songkhram, Mae khong and other rivers in northeast Thailand. The general public knew the ecological usefulness of the swamps where spread along the banks of the sea ${ }^{[2]}$ but some particular people did not know the ecological usefulness of Pubung Patham where spread along the bank of the rivers. Considering the diversity of the ecological elements of flood plains that consist of water, fertile soil and other extra surroundings, it is an original of living things that can adapt themselves according to the high level of water during flood and low level of water during drought of each year ${ }^{[3]}$.

\section{MATERIALS AND METHODS}

Population and sample: The instruments used for data collecting were an observation form, an interview form and a community participation note taking form according to AIC process. AIC process was operated as follow: A = Appreciation, I: Influence, C: Control. The sample was three groups consisted of 30 key informants, 159 casual informants and 42 general informants.

\section{RESULTS AND DISCUSSION}

The research results revealed that some Pabung Patham located in the Chi River Basin was just remained the name but disappeared in real earth because it was become a rice field, a fish hatchery, a forest monastery, a public health station and some was become a concession forest that government allowed the private firm for wood cutting. As above-mentioned, all factors caused a reduction of forest, a natural peril from the yearly floods, an inefficient in season rice field farming. Thus, people changed their old occupation from rice field farming to vegetable cultivation; for example Muang Yai Village, Mahasarakham Province. Kut Lom and Wang Wern Village, Khon Kaen Province, the majority of women were employed to weave silk. Ban Lhao Yhai Village, Yasothon Province, women group established a cooperating business venture in order to produces their products and share earnings amongst the members. The famous product of these villages was peanut-brittle sweets. So the project of planting three kinds of tree and gaining four ecological and cultural uses, people agreed with this project. Because it enhanced a lot of usefulness for community and reduced effectively the awful situation of global warming, drought, storm and flood.

\section{CONCLUSION}

According to the results of the research entitled "conservation, Renewability and Development of Pabung Patham "Flood Plains" in The Chi River Basin by community Participation" It was found that. (1) At present Pabung Patham have been fading away from new generations memories because they have known only community forest or "Pa Chum Chon". Many kinds of plants, herbs, aquatic animals, wild animals and insects are reduced. Furthermore, some kind of them are become extinct in the future if no conservation (2) conservations by community participation according to AIC process was operated as follows: A: Appreciation, it was a process of constructing an appreciation. I: Influence, it was a process of constructing an influence on the way to develop. C: Control, it was a process of constructing the way to control the project ${ }^{[4]}$.

In this research control about planting threekinds of tree and gaining four uses according to the feature of cultural landscapes of Pabung Patham that consisted of planting trees for construction, Trees for fruit and trees for fuel. Forest enhanced ecological balance in these ways. (1) Enhancing oxygen for human beings. (2) Enhancing water for human beings. (3) Enhancing fertility of soil and (4) enhancing the diversities of culture in case of the forest that located in different ecology. Four cultural uses that we gained from forest classified into: (1) food was gained from plants, insects, wild animals, aquatic animals. (2) Herbal medicine. (3) Fuel was gained from trees. (4) Construction parts were gained from trees ${ }^{[5]}$.

\section{ACKNOWLEDGEMENT}

The research has been supported generously by The Research Institute of Northeastern Art and Culture Mahasarakham University. The authors would like to express their sincere appreciation for all of the support provided.

\section{REFERENCES}

1. Boonchai, S., 2005. The Geography of Thailand. Odien Store, Bangkok, ISBN: 974-971-265-X. 
2. Chaipattana Foundation, 2009. Conservation and Development of Natural Resources and Environment.

3. Gergel, S.E., M.D. Dixon and M.G. Turner, 2002. Consequences of Human Altered Floods: Levees, Floods and Floodplain Forest along the Wisconsin river. Ecol. Appli., 12: 1755-1770. http://cat.inist.fr/?aModele=afficheN\&cpsidt=1445 2337
4. Office of Public Policy Development for Quality of Life. 2007. Pabung Patham: Swamp Forest of the Isan River Basin. Bangkok: Ministry of Social Development and Human Security. http://www.thainhf.org/index.php?module=news\& page2 $=$ detail\&id $=5$

5. Wattanasiriwan, P., 2002. The participatory and creative workshop.

http://advisor.anamai.moph.go.th/tamra/AIC/aic02.html 